\title{
Lupus Anticoagulant in Myasthenia Gravis Associated with IgM Gammopathy
}

\author{
Shozo Ishikawa, Yutaka KomiYama*, Hikaru KobaYashi**, Jun TsuYuZaKi, Shinichi ToKunaga***, \\ Atsushi MiYAZAKI****, Norinao HANYU***** and Shu-ichi IKEDA
}

\begin{abstract}
The plasma of a patient with myasthenia gravis had strong lupus anticoagulant activity and his IgM paraprotein displayed non-specific inhibition to coagulation factors IX, XI, XII, prekallikrein, and high molecular weight kininogen. He was placed on prednisolone, which resulted in improvement in his myasthenic symptoms, but the prolongation of APTT and macroglobulinemia remained. Double filtration plasmapheresis successfully decreased the serum IgM level from $1,190 \mathrm{mg} / \mathrm{dl}$ to $375 \mathrm{mg} / \mathrm{dl}$ and APTT improved from $58 \mathrm{~s}$ to $38 \mathrm{~s}$. Myasthenia gravis is frequently associated with other autoimmune diseases, but the association with lupus anticoagulant and IgM gammopathy is rare.
\end{abstract}

(Internal Medicine 40: 952-955, 2001)

Key words: double filtration plasmapheresis, coagulation factor

\section{Introduction}

The association of myasthenia gravis (MG) with other autoimmune disorders has been reported. If the cases from different series are combined, $3.6 \%$ had evidence of one of these diseases (1). There are several reports on the coexistence of polymyositis, but only sporadic cases of dermatomyositis with MG have been documented (2). Meanwhile, lupus anticoagulant (LA) antibodies might be detected in patients with MG (3). They are usually polyclonal IgG or IgM antibodies in low concentrations that do not produce a visible abnormal M-component on serum electrophoresis, but in sporadic cases associated with B-cell disorders including multiple myeloma and Waldenström's macroglobulinemia (4), their monoclonal paraprotein functioned as an anticoagulant (5).
Here, we report a patient with MG who presented with marked prolongation of activated partial thromboplastin time (APTT), IgM gammopathy, and violaceous erythema. Laboratory studies showed IgM isolated from the plasma to possess strong LA activity.

\section{Case Report}

A 49-year-old man presented with ptosis and diplopia in May 1998. During the first month after the onset the patient noticed difficulty swallowing accompanied by a nasal-sounding voice. In July he developed erythematous lesions on his left forearm which extended to the face, chest, and the other forearm over the next several subsequent weeks. Difficulty swallowing made him lose $10 \mathrm{~kg}$ in body weight every two months and he developed increasing weakness in the course of the day in his proximal limb muscles and neck.

He was admitted to Nagano Red Cross Hospital in September 1998. On examination, he exhibited symmetric confluent macular violaceous erythema overlying the extensor aspects of the upper arms and forearms, the $\mathrm{V}$ area of the anterior neck and upper chest, the central aspect of the face and forehead, and the scalp (Fig. 1). His eyelids were edematous but did not look violaceous and there were no Gottron's papules. The patient showed abnormal weakness and fatigability in all voluntary muscles. Edrophonium testing was strongly positive and anticholinesterase therapy produced a definite improvement in his symptoms. Electromyography showed no significant decremental or incremental responses in the amplitude of the compound muscle action potential with repetitive ulnar nerve stimulation. No enlargement of the thymus and interstitial pneumonitis were seen radiologically.

Laboratory examination revealed a hemoglobin level of 15.4 $\mathrm{g} / \mathrm{dl}$, leukocyte count of $4,200 / \mu 1$, lymphocyte count of $700 / \mu \mathrm{l}$, and a platelet count of $11.3 \times 10^{4} / \mu \mathrm{l}$. The $\mathrm{C}$-reactive peptide was $0.07 \mathrm{mg} / \mathrm{dl}$ and the ESR was $37 \mathrm{~mm}$ in 1 hour. Creatine kinase was $72 \mathrm{U} / l$ (normal 43-272 $\mathrm{U} / l$ ).

From the Department of Medicine (Neurology), Shinshu University School of Medicine, Matsumoto, *the Department of Clinical Sciences and Laboratory Medicine, Kansai Medical University, Osaka, **the Department of Hematology, ${ }^{* * *}$ the Department of Nephrology, ****the Départment of Dermatology and *****the Department of Neurology, Nagano Red-Cross Hospital, Nagano

Received for publication October 24, 2000; Accepted for publication April 22, 2001

Reprint requests should be addressed to Dr. Shozo Ishikawa, the Department of Medicine (Neurology), Shinshu University School of Medicine, 3-1-1 Asahi, Matsumoto 390-8621 

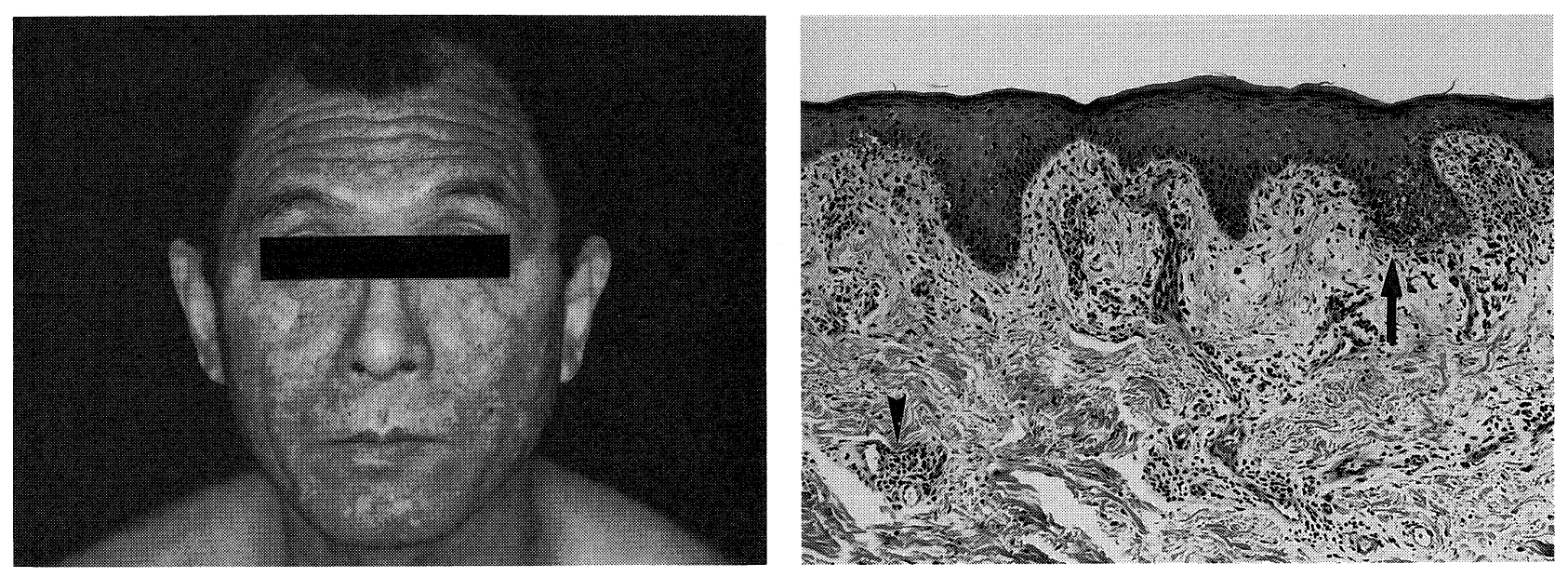

Figure 1. Left: Symmetric confluent macular violaceous erythema on the face. Right: Skin biopsy showed dermal edema, focal areas of perivascular mononuclear cell infiltration in the dermis (arrowhead), and liquefactive change of the basal layer of the epidermis (arrow) (HE stain, $\times 80$ ).

The total serum protein was $6.8 \mathrm{~g} / \mathrm{dl}$ and the serum albumin was $3.2 \mathrm{~g} / \mathrm{dl}$. The serum immunoglobulin levels were $\operatorname{IgG} 1,140$ $\mathrm{mg} / \mathrm{dl}$ (normal 600-2,000 mg/dl), IgA $111 \mathrm{mg} / \mathrm{dl}$ (normal 50$400 \mathrm{mg} / \mathrm{dl}$ ), IgM $1,210 \mathrm{mg} / \mathrm{dl}$ (normal 40-250 mg/dl), IgE 116 $\mathrm{U} / \mathrm{ml}$ (normal $<180 \mathrm{U} / \mathrm{ml}$ ). Serum electrophoresis and immunoelectrophoresis showed hypergammaglobulinemia with a monoclonal gammopathy IgM $\kappa$. No rheumatoid factor was detected. Serum C3 level was $39 \mathrm{mg} / \mathrm{dl}$ (normal 60-116 mg/ $\mathrm{dl}$ ), C4 was less than $8 \mathrm{mg} / \mathrm{dl}$ (normal $10-12 \mathrm{mg} / \mathrm{dl}$ ), and CH50 was $14.5 \mathrm{U} / \mathrm{ml}$ (normal 30-100 U/ml), but the level of immune complex composed of IgG was not elevated; IC (C1q) was 0.7 $\mu \mathrm{g} / \mathrm{dl}$ (normal $<1.5 \mu \mathrm{g} / \mathrm{dl}$ ) and IC (C3d) was $6.9 \mu \mathrm{g} / \mathrm{dl}$ (normal $<13 \mu \mathrm{g} / \mathrm{dl})$. Antinuclear antibodies were not present and antibodies to dsDNA, ssDNA, Sm, SS-A, SS-B, Jo1, RNP, Scl70, p-ANCA were also absent. The titer of IgG acetylcholine receptor antibody was $29.6 \mathrm{nmol} / l$ (normal $<0.2 \mathrm{nmol} / l$ ).

Prothrombin time was $11 \mathrm{~s}$ (normal 10-12 s), APTT was significantly prolonged to $79 \mathrm{~s}(26-35 \mathrm{~s})$, and thrombin time was more than $150 \%$ ( $>70 \%)$. Lupus anticoagulant (LA) was positive with APTT mixing test, and APTT with diluted tissue thromboplastin assay was more than $150 \mathrm{~s} \mathrm{(normal}<55.6 \mathrm{~s}$ ), with platelet neutralization procedure $133.5 \mathrm{~s}$ (normal $<6.3 \mathrm{~s}$ ). The IgG anti-cardiolipin antibody (aCL) was 2.5 (normal $<1$ ) and IgM aCL was $0.6(<1)$. Anticoagulant activity of $\beta 2$-glycoprotein I ( $\beta 2$-GPI) and anti-platelet antibody was not detected. The patient presented with no recurrent widespread vascular thrombosis and no laboratory abnormal findings consisting of a reduced plasma fibrinogen concentration and a high level of plasma D-dimer. Serum cryoglobulin was detected but was too weakly positive to classify its type. The patient developed proteinuria at a level of $24 \mathrm{mg} / \mathrm{dl}$ and Bense-Jones protein $\kappa$ was positive. Bone marrow biopsy proved normoplastic and there was no lymphoplasmacytic infiltrate.

Skin biopsy from the forearm showed dermal edema, focal areas of perivascular mononuclear cell infiltration in the der- mis, and liquefactive change of the basal layer of the epidermis (Fig. 1). Alcian blue ( $\mathrm{pH} 2.5$ ) staining revealed mucin deposition on superficial dermis, but lupus band tests showed no deposits of immunoglobulin or complement along the dermalepidermal junction and dermal connective tissue. These findings suggested that his skin lesion was compatible with dermatomyositis.

On September 3, 7, and 10, immunoadsorption was performed using a phenylalanine column. His dysphagia and generalized fatigability improved only for a few days after immunoadsorptions, so prednisolone was administered at an initial dose of $10 \mathrm{mg}$ per day. In October he showed remarkable improvement with prednisolone at a dose of $30 \mathrm{mg}$ per day, and there was no muscle weakness except for in his neck. However, the serum IgM level was still high at $1,190 \mathrm{mg} / \mathrm{dl}$, while serum complement levels were C $342 \mathrm{mg} / \mathrm{dl}$, C4 less than $8 \mathrm{mg} / \mathrm{dl}$, and CH50 $16.3 \mathrm{U} / \mathrm{ml}$. APTT remained prolonged at $58 \mathrm{~s}$.

In order to investigate the intrinsic coagulation pathway, factors XI, XII, prekallikrein, and high molecular weight kininogen (HMWKg) were assayed using their deficient plasma. The value of the factor XI antigen measured by our ELISA system (6) was normal: $3.1 \mu \mathrm{g} / \mathrm{ml}, 78 \%$ of control. However, clotting activities found for these factors were significantly low and XII was $6.2 \%$ of control plasma, XI was $2.3 \%$, IX was $10 \%$, PK was $0.9 \%$, and HMWKg was $9.5 \%$ (Table 1 ). To characterize the nature of anti-coagulant activity in the patient's plasma, we analyzed the plasma using high performance gel permeation chromatography with Superdex $200 \mathrm{HR}$. As shown in Table 2, the inhibitor activity was found in the large second peak derived from IgM, whereas no inhibitor activity was detected in the $\operatorname{IgG}$ fraction of patient plasma, or in the IgM and $\mathrm{IgG}$ of normal pooled plasma.

To remove pathognomonic monoclonal IgM, double filtration plasmapheresis (DFPP) was performed using a plasmasepa- 
ISHIKAWA et al

Table 1. Sequential Measurement of IgM, APTT, and Coagulation Factor Activities (\%)

\begin{tabular}{llccccccc}
\hline \multicolumn{2}{l}{ date of therapy } & $\begin{array}{c}\text { IgM } \\
\text { (mg/dl) }\end{array}$ & $\begin{array}{c}\text { APTT } \\
(\mathrm{sec})\end{array}$ & XII & XI & IX & PK & HMWKg \\
\hline 4 Nov. & before 1st DFPP & 1190 & 58.4 & 6.2 & 2.3 & 10 & 0.9 & 9.5 \\
& 1 hr after 1st DFPP & 681 & 47.7 & 6.8 & 3.8 & 11 & 0.9 & 18 \\
5 Nov. & $16 \mathrm{hr}$ after 1st DFPP & 662 & 43.1 & 8 & 3.9 & 12.5 & 1 & 15 \\
6 Nov. before 2nd DFPP & 769 & 43.9 & 9 & 3.6 & 12 & 1.2 & 16 \\
7 Nov. 16 hr after 2nd DFPP & 375 & 39.7 & 7 & 3.1 & 12.5 & 1.1 & 23 \\
9 Nov. 64 hr after 2nd DFPP & 617 & 38.4 & 9 & 3.1 & 11.5 & 1.3 & 19 \\
\hline
\end{tabular}

DFPP: double filtration plasma pheresis, PK: prekallikrein, HMWKg:high molecular weight kininogen. Note the significant drop in the levels of IgM and APTT after two DFPP treatments.

Table 2. Effects of Patient's IgM on Activities of Factor IX, XI, XII, Prekallikrein, and High Molecular Weight Kininogen

\begin{tabular}{lcccccc}
\hline & XII & XI & IX & VIII & PK & HMWKg \\
\hline control IgG & 98 & 100 & 100 & 70 & 80 & 76 \\
control IgM & 92 & 100 & 100 & 70 & 78 & 54 \\
patient IgG & 92 & 100 & 100 & 70 & 73 & 74 \\
patient IgM & 27 & 11.5 & 4.8 & 53 & 14.5 & 16 \\
\hline
\end{tabular}

PK: prekallikrein, HMWKg: high molecular weight kininogen. The addition of control IgG, IgM, and patient's IgG had no effect on any of the activities.

rator with a pore size of $0.2 \mu \mathrm{m}$. It successfully decreased the IgM level from $1,190 \mathrm{mg} / \mathrm{dl}$ to $375 \mathrm{mg} / \mathrm{dl}$, and APTT improved from $58 \mathrm{~s}$ to $38 \mathrm{~s}$. The levels of individual coagulation factors increased gradually but still remained low and the effect continued only for a few days (Table 1).

\section{Discussion}

LA has been sporadically detected in patients with MG, but there was no correlation between the presence of LA and severity of MG or titer of anti-acetylcholine receptor antibodies (3). In general, LA antibodies are polyclonal antibodies and individuals with LA rarely show a decrease in only a single coagulation factor. Unique hemorrhagic diathesis, however, occurs in association with the B-cell disorders that produce a probably monoclonal paraprotein which could be identified as an immunoglobulin inhibitor of a major component of the coagulation cascade or phospholipid $(4,5)$. The presence of monoclonal gammopathy in the serum of a sporadic patient with MG was documented (7), but no association of M-component or MG has been indicated. In the present case, there was no lymphoplasmacytic infiltrate in the patient's bone marrow, and it was not possible to judge whether his M-component was due to a specific anticoagulant antibody.

The patient's muscle weakness and swallowing difficulty were definitely improved by edrophonium tesing and anticho- linesterase therapy, and the patient had normal creatine kinase levels, thus we considered that his myasthenic syndrome could be caused by MG, not dermatomyositis, although muscle biopsy was not performed. However, the early histologic appearance of the skin biopsy in patients with dermatomyositis is similar to or indistinguishable from that seen in systemic lupus erythematosus (SLE). Our patient developed no criteria of SLE but he showed depressed serum complement levels with strikingly low C-reactive protein level, thrombocytopenia, lymphocytopenia, and LA is often detected in SLE. Myasthenic manifestations preceded symptoms with SLE in $72 \%$ documented cases of MG associated with SLE (8). Meticulous evaluation and long-term observation should be required before the diagnosis is established.

This case showed generalized myasthenic symptoms and thymectomy was definitely recommendable, but it might have led to the emergence of new autoimmune conditions. Severe SLE (9), antiphospholipid syndrome (10), and Waldenström's macroglobulinemia (11) have been induced or worsened following thymectomy, pointing to the importance of immune dysregulation in the induction of these autoimmune diseases. Meanwhile, thrombosis has been reported in up to 30 percent of patients with lupus anticoagulant, and the risk of thrombosis is higher in patients with IgG antibodies than with IgM antibodies (12). We have observed the present patient carefully with neither anticoagulation therapy nor performing thymectomy; he is maintained on prednisolone at a dose of $20 \mathrm{mg}$ per day without deterioration of his myasthenic symptoms, erythema, or gammopathy. If the serum level of IgM increases and widespread vascular thrombosis develops, additional immunosuppressive or anticoagulation therapy might be inavoidable.

Acknowledgements: The authors thank Akiyo Nomura for her assistance in preparing the blood coagulation tests.

\section{References}

1) Engel AG. Myasthenia gravis and myasthenic syndromes. in: Handbook of Clinical Neurology, vol 62, Myopathies, Rowland LP, DiMauro S, Eds. Elsevier, Amsterdam, 1992: 391-455.

2) Vasilescu C, Bucur G, Petrovici A, et al. Myasthenia in patients with der- 


\section{Lupus Angicoagulant in Myasthenia Gravis}

matomyositis: clinical, electrophysiological and ultrastructural studies. J Neurol Sci 38: 129-144, 1978.

3) Kinoshita I, Motomura M, Nagasato K, et al. Antiphospholipid antibodies in patients with myasthenia gravis. Acta Med Nagasaki 39: 41-44, 1994.

4) Wisloff F, Michaelsen TE, Godal HC. Monoclonal IgM with lupus anticoagulant activity in a case of Waldenström's macroglobulinaemia. Eur J Haematol 38: 456-60, 1987.

5) Kandiah DA, Sali A, Sheng Y, et al. Current insights into the "antiphospholipid" syndrome: clinical, immunological, and molecular aspects. Adv Immunol 70: 507-563, 1998.

6) Komiyama $Y$, Nishikado $H$, Masuda $M$, et al. A rapid enzyme-linked immunosorbent assay for human factor XI. Thromb Res 50: 329-334, 1988.

7) Somer H, Pirskanen R, Lefvert AK, et al. Myasthenia gravis and mono- clonal IgG gammopathy. Neurology 29: 842-847, 1979.

8) Ciaccio M, Parodi A, Rebora A. Myasthenia gravis and lupus erythematosus. Int J Dermatol 28: 317-320, 1989.

9) Mevorach D, Perrot S, Buchanan NM, et al. Appearance of systemic lupus erythematosus after thymectomy: four case reports and review of the literature. Lupus 4: 33-37, 1995.

10) Shoenfeld $Y$, Lorber $M$, Yucel $T$, et al. Primary antiphospholipid syndrome emerging following thymectomy for myasthenia gravis: additional evidence for the kaleidoscope of autoimmunity. Lupus 6: 474-476, 1997.

11) Bartoloni C, Scoppetta C, Flamini G, et al. Waldenström's macroglobulinemia and myasthenia gravis. J Clin Lab Immunol 6: 275-278, 1981.

12) Triplett DA, Brandt JT, Musgrave KA, et al. The relationship between lupus anticoagulants and antibodies to phospholipid. JAMA 259: 550$554,1988$. 